Demiryolu Mühendisliği

Temmuz 2021

Sayı:14, Sayfa: 154-166

Araştırma Makalesi
Railway Engineering

July 2021

Issue:14, Page: 154-166

Research Article

doi: 10.47072/demiryolu.941405

http://dergipark.org.tr/demiryolu

e-ISSN: 2687-2463, ISSN: 2149-1607

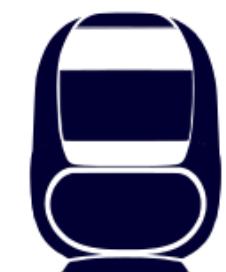

\title{
CBTC Sistemlerinde Tolere Edilebilir Seyahat Süre Artışı için Enerji Verimliliği Stratejilerinin Karşılaştırılması
}

\author{
Serhat BOYNUKALIN*1(D), Süleyman AÇIKBAŞ²(D), M. Turan SÖYLEMEZ ${ }^{3}$ (D) \\ ${ }^{1}$ Istanbul Teknik Üniversitesi, Lisansüstü Eğitim Enstitüsü, İstanbul, Türkiye \\ ${ }^{2}$ HI-SIM Teknoloji Mühendislik Ltd. Şti., İstanbul, Türkiye \\ ${ }^{3}$ Ístanbul Teknik Üniversitesi, Elektrik-Elektronik Fakültesi, İstanbul, Türkiye
}

*boynukalin@itu.edu.tr

(Alını̧̧/Received: 23.05.2021, Kabul/Accepted: 24.06.2021, Yayımlama/Published: 31.07.2021)

Öz: Günümüzde, birçok metro hattı projesinde sinyalizasyon sistemi olarak haberleşme tabanlı tren kontrolü (CBTC) sistemleri kullanılmaktadır. Otomasyon seviyesi-2 (GoA2) veya üzerinde bir otomasyon seviyesine sahip sinyalizasyon sistemi trenleri, önceden tanımlanmış hız profillerini dikkate alarak sürmekte ve tren trafiğini yönetmektedir. CBTC sistemlerine ilişkin IEEE std. 1474 standardı özellikle trenin hızlanması (ivmesi), trenin boșta gitmesi ve trenin frenlemesi gibi parametreleri enerji optimizasyon algoritması için kullanabileceğini tanımlamaktadır. Bu makalede trenlerin gidiş ve dönüş yönlerindeki toplam seyahat süresinde tam performanslı kullanıma (tam güç modu) göre, işletme firmalarının kabul edebileceği ve tren sayısını arttırmayacak olan, \%4 uzatmaya yol açan farklı parametre setlerinin ve boșta gitme stratejisinin, sistemin enerji tüketiminde ne kadar avantaj sağladığ 1 örnek bir metro hattı verileri ile incelenmiş ve ele alınan durumlarda boşta gitme stratejisinin \%21,34'e kadar daha az enerji tüketimi oluşturacağı gösterilmiştir. Çalışmada hem tren performans/hareket hem de cer gücü sistemi yük akış analizini birlikte gerçekleștirebilen güçlü bir raylı sistem simülasyon yazılımı olan Hi-SimuX - Raylı Sistem Simülasyon Yazılımı ile farklı performans parametre setleri ve boşta gitme stratejisine ait simülasyonlar gerçekleştirilmiştir. Tek tren durumuna ilişkin senaryolarda tren performans simülasyonları ve ardından çok sayıda trenin farklı işletme sıklıkları ile koşturulduğu çoklu tren senaryolarına ait cer gücü sistemi simülasyonları gerçekleştirilmiștir. Hem tek tren durumu için yapılan tren performans simülasyonları hem de farklı işletme sıklıklarının olduğu çoklu tren durumu için koşturulan cer gücü simülasyonlarındaki enerji tüketimi değerleri kıyaslanmıştır. Yapılan simülasyonlar, tam güç moduna göre aynı miktarda süre uzatımına yol açan boşta gitme stratejisinin kullanımının performans parametrelerinin kullanıldığı diğer enerji optimizasyon yaklaşımlarına göre daha fazla enerji tasarrufu imkânı verdiğini göstermiştir. Çoklu tren işletme durumunda işletme sıklığına bağlı olarak, boşta gitme stratejisi \%14,1121,34 arasında tasarruf sağlarken ikinci iyi olan stratejide ise \%8,7-11,46 arasında enerji tasarrufu sağlamaktadır.

Anahtar kelimeler: Tren performans simülasyonu, Cer gücü simülasyonu, Raylı sistem, Enerji verimliliği, Boşta gitme, Sinyalizasyon

\section{Comparison of Energy Optimization Strategies in CBTC System for a Tolerable Travel Time Increase}

\begin{abstract}
Nowadays, communication-based train control (CBTC) systems are used as signaling systems in many metro line projects. The signaling system with grade of automation level-2 (GoA2) or higher drives trains according to predefined speed profiles and manage the train traffic. The IEEE 1474 standard for CBTC systems defines that the signaling system can use performance parameters such as train acceleration, braking and coasting for the energy optimization algorithm. In this article, different parameter sets and coasting strategy that cause $4 \%$ increase, which can be tolerated and accepted by the metro operation companies, in total travel time compared to the full performance (All-out) mode are examined on a sample metro line and their effects on the energy consumption of the system are compared. It is shown that the coasting strategy consumes up to $21,34 \%$ less energy. Detailed simulations with different performance parameter sets and the coasting strategy are performed with Hi-SimuX - Rail System Simulation Software, which can perform both train performance/movement and traction power simulations together. Single train

Atıf için/Cite as: S. Boynukalın, S. Açıkbaş, M. T. Söylemez, "CBTC sistemlerinde tolere edilebilir seyahat süresi artışı için enerji verimliliği stratejilerinin karşılaştırılması," Demiryolu Mühendisliği, no. 14, pp. 154-166, July 2021. doi: $10.47072 /$ demiryolu. 941405
\end{abstract}


and then traction power simulations with multi-trains where many trains are run with different operating headways are run. Energy consumption values in both train performance simulations for a single train situation and traction power simulations with multi-train situations for different operating headways are compared. Simulation results have shown that the coasting strategy provides more energy savings compared to other energy optimization approaches that use performance parameters. In case of multi-train operation, depending on the operation headway, the coasting strategy provides energy reduction between 14,11$21,34 \%$, while the second-best strategy provides energy reduction between $8,7-11,46 \%$.

Keywords: Train performance simulation, Traction power simulation, Rail system, Energy efficiency, Coasting, Signaling

\section{Giriş}

Elektrikli raylı sistem taşımacıllğının diğer toplu taşıma sistemlerine göre enerji tüketimi açısından daha verimli olduğu bilinmektedir. Raylı sistemlerde daha düşük karbon salınımı için birçok farklı strateji uygulanabilir. Bunlar istasyon tasarımı ve konumlandırması, tren tasarımı ve cer paketinin optimizasyonu, rejeneratif enerji kullanımını arttıracak sistemlerin kullanımı ve trenlerin hız profillerinin optimizasyonunun yapılması gibi özetlenebilir. Gonzalez-Gil ve arkadaşları [1], Douglas ve arkadaşları [2], Botte ve D’Acierno (2018) [3], Popescu ve Bitoleanu [4] raylı sistemlerde enerji verimliliği stratejileri için kapsamlı literatür taramaları yaparak bu konuda yapılmış çalışmaları özetlemişlerdir. Su ve arkadaşları [5] farklı stratejilere göre enerji tasarruf potansiyelini Beijing Yizhuang hattı verileri üzerinde incelemiştir. Stratejilerde enerji verimli sürüş, tren kütlesi, hattın eğimi, maksimum hızlanma ve frenleme değerleri ve rejeneratif frenleme dikkate alınarak incelenmiştir. Parametreler teker teker incelenmiş ve enerji verimli sürüş stratejisinin \%12,07 ye kadar enerji tasarruf sağlayabildiği görülmüştür.

Modern raylı sistemlerde, trenin hızı sinyalizasyon sistemi tarafından kontrol edilir ve düzenlenir. Yeni veya yenilenmiş metro sistemleri GoA2 ve üstü otomasyon seviyesine sahip CBTC sinyalizasyon sistemi ile donatılmaktadır. Bu sistemlerde trenler önceden tanımlanmış otomatik tren sürüş (ATO) hız profillerine göre sürülmektedir. Farklı performans parametre set değerlerine karş1l1k düşen birden fazla sayida performans seviyesine göre tren sürüşü gerçekleştirilebilmektedir. IEEE Std. 1474.1 standardı [6] CBTC sisteminin otomatik tren denetimi (ATS) alt sistemi ile enerji optimizasyonu yap1labileceğinden bahsetmektedir. Standardın CBTC sistemi içinde enerji verimliliği algoritmasının tren ivmelenmesi, tren boşta gitmesi ve tren frenlemesi parametrelerini kullanabileceğini işaret etmektedir. Bütün bu parametreler, trenlerin terminaller arasındaki seyahat süresine ve enerji tüketimlerine etki etmektedir.

Dominguez ve arkadaşları [7] Madrid Metrosu Hat 3'ün sinyalizasyon sistemindeki ATO hız profilleri üzerinde çalışarak yeni hız profilleri önermiştir. Önerilen hız profillerinin eski hız profiline göre sağladığ1 enerji tasarrufunun yaklaşı \%13 olduğu saha ölçümleriyle gösterilmiştir. Rongwu ve arkadaşları [8], ATS'nin her seviyede maksimum hızı \%10 azaltan 5 farklı performans seviyesine sahip olduğu bir sistemi incelemiştir. Makalede yalnızca maksimum hız azaltmaya dayalı performans seviyesinin en etkili yaklaşım olmadığı, çünkü hat üzerindeki yokuş aşağı eğim alanlarından yararlanamadığı belirtilmektedir.

IEEE standardının ilgili maddesi için sinyalizasyon sistemi sağlayıcıları arasında farklı çıkarım ve yaklaşımların olduğu ve CBTC sisteminin enerji optimizasyon işlevi hakkında çoğu zaman son kullanıcıya çok fazla detay vermediği gözlemlenmiştir. İşletmecilerin de bu özelliğin sağlayabileceği enerji tasarruf potansiyelini net bir şekilde anlamadığı ve bu özelliği kullanmadığ1 görülmektedir [9]. Örnek bir metro hattı üzerinde tam güç işletme durumuna göre yolculuk süresini $\% 2,7$ ila \% 19,6 arttıran farklı stratejiler ele alınmış ve boşta gitme stratejisinin daha fazla enerji tasarrufu sağlayacağını göstermiştir. 
$\mathrm{Bu}$ makale, tam güç işletme durumuna göre toplam yolculuk süresi artışını gerçek işletme koşullarında rahatlıkla uygulanabilecek bir değer olan \%4 olarak gerçekleyen tren hızlanma ivmesi, frenleme ivmesi ve maksimum hız performans parametre setleri ve boşta gitme stratejisinin kullanılması ile elde edilecek olan enerji tasarruf oranlarını karşılaştırmaktadır.

Çalışma sonucunda, boşta gitme stratejisinin üstünlüğü gösterilmiştir. Ayrıca, tek tren ve çoklu tren-çoklu hat simülasyonları gerçekleştirilerek sonuçları detaylı şekilde kıyaslanmış ve özellikle tek tren simülasyonları sonucunda trenlerin yardımcı güç sisteminin tüketiminin hesaba katılmamasının enerji tasarrufu sonuçları üzerinde bazı durumlarda çok iyimser ve yanıltıcı olabileceği gösterilmiştir.

Makalenin geri kalanı aşağıdaki şekildedir: 2. ve 3. bölümlerde sırasıyla makalenin hazırlanmasında kullanılmış olan simülasyon yazılımı ve simülasyon testlerinin gerçekleştirildiği metro hattının ve kullanılan trenin ana parametreleri kısaca tanıtılmaktadır. Bölüm 4'te incelenen enerji optimizasyonu stratejileri özetlenmektedir. Tek tren performans simülasyon sonuçları Bölüm 5'te verilmiştir. Çoklu tren-çoklu hat cer gücü simülasyon sonuçları ve enerji optimizasyonu stratejileri arasındaki karşılaştırmanın yanı sıra tek tren performans simülasyon sonuçlarına göre karşılaştırmaya ilişkin bir tartışma Bölüm 6'da verilmiştir. Makale, Bölüm 7'deki ana bulguların bir özeti ile sonlandırılmaktadır.

\section{Raylı Sistem Simülasyon Paketi: Hi-SimuX}

Bir raylı sistemin elektrik yük akış analizi, çok sayıda doğrusal olmayan denklemin çözülmesini içerir. Bu tür hesaplamalarda, boyutları hattın uzunluğuna ve inceleme için seçilen parametrelere bağlı olan seyrek matrislerin yinelemeli çözümü gereklidir. Hattaki trenlerin hareketine göre elektrik devresinin parametreleri anlık değişmekte olup bu tür analizler sadece simülasyon programları yardımıyla gerçekleştirilebilir.

$\mathrm{Bu}$ çalışmadaki farklı performans parametre setleri ve boşta gitme stratejileri için yapılan simülasyonlar Hi-SimuX adı verilen hem tek hem de çok hatlı, çok trenli işletme durumlarının modellemesini detaylı bir şekilde yapabilen simülasyon paketi ile yapılmıştır. Simülasyon yazılımının temel özellikleri [10] detaylı şekilde anlatılmış ve www.hisim.com.tr sitesinde yeteneklerine ilişkin çok daha detaylı bilgi verilmiştir.

Hi-SimuX, raylı sistemlerin kullanıcı dostu/kullanımı kolay bir ortamda simüle edilebilmesine imkân verir. Hem yeni hat hem de iyileştirme projelerinde ve çok sayıda akademik araştırma ve yayında tren operasyonu ve cer sistemi simülasyonları için kullanılmıştır. Hi-SimuX, IEEE CBTC standartlarında açıklanan güvenli frenleme modelinin yanı sıra araçların rejeneratif frenleme ve gerilime bağlı akım sınırlama işlevini de dikkate alır. Yazılımın çıktıları gerçek saha ölçümleriyle karşılaştırılmış ve simülasyon sonuçlarının saha ölçüm değerlerine çok yakın olduğu görülmüştür.

\section{Metro Hattının ve Trenin Özellikleri}

Testlerde kullanılan metro hattının uzunluğu $13,8 \mathrm{~km}$ 'dir ve 11 yolcu istasyonu (PS) bulunmaktadır. 7 Cer istasyonu (SS) ile iki hat beslenmektedir. Simülasyonlarda kullanılan hattın genel görünüm Şekil 1'de verilmiştir. Şekil 1'deki x ekseni ölçeklendirilmiştir. L1 (Hat 1) bat1 yönü ve L2 (Hat 2) doğu yönü tren operasyonları içindir. 


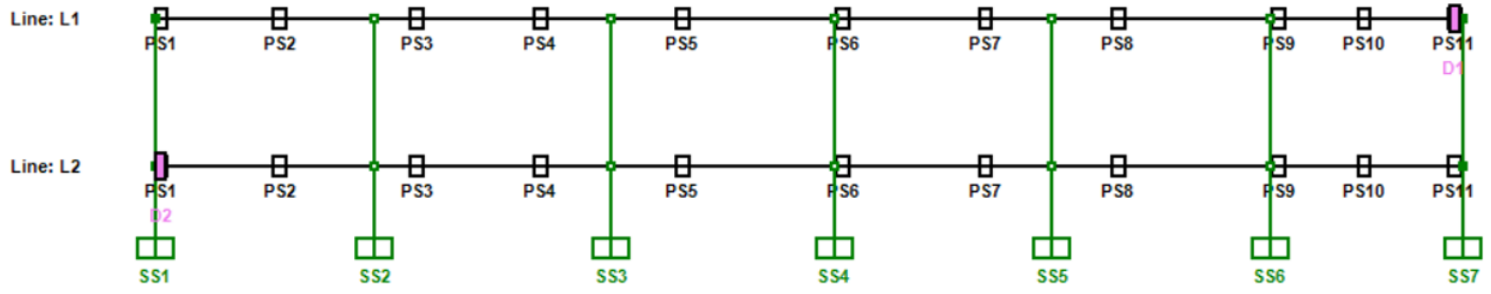

Şekil 1. Metro hattı genel gösterimi

Hattın dikey profili Şekil 2'de verilmiştir. Hat üzerindeki maksimum eğim değeri \%3.5'tir.

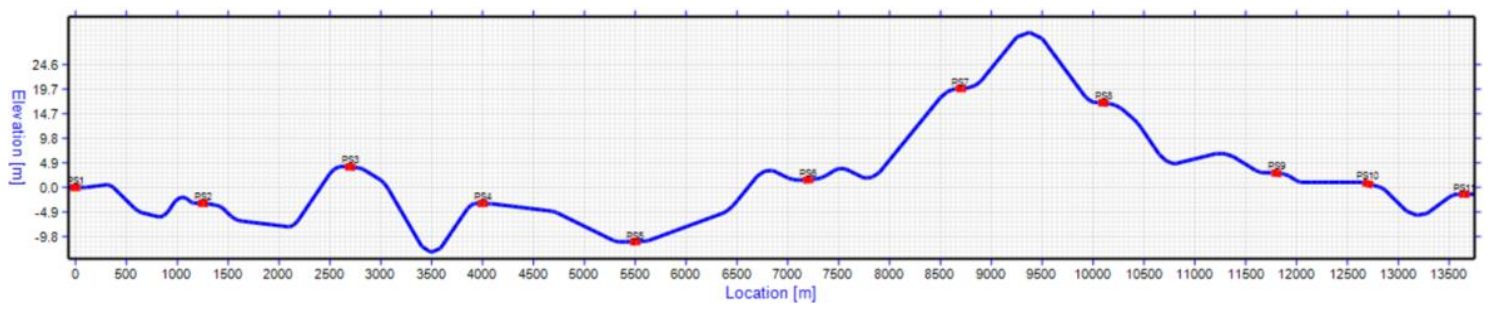

Şekil 2. Metro hattı dikey profili

İstasyon (PS) orta noktaları Tablo 1'de verilmiştir. İstasyonlar arası mesafeler 900 ile $1700 \mathrm{~m}$ arasında değişmektedir. Platform uzunluğu 100 m'dir ve trenler, istasyonda dururken orta noktası platformun orta noktası ile hizalanır. Platformlarda bekleme süresi tek tren performans simülasyonlarında sabit $20 \mathrm{~s}$, çoklu tren çoklu hat cer gücü simülasyonlarında 16-24 s arasında, ort. $20 \mathrm{~s}$ ve std. sapma değeri $2 \mathrm{~s}$ olan normal dağılım kullanılarak rastgele değerler atanmıştır.

Tablo 1. İstasyon orta noktaları

\begin{tabular}{lccccccccccc}
\hline İstasyon Numaras1 & PS1 & PS2 & PS3 & PS4 & PS5 & PS6 & PS7 & PS8 & PS9 & PS10 & PS11 \\
\hline Orta Noktas $1(\mathrm{~m})$ & 0 & 1250 & 2700 & 4000 & 5500 & 7200 & 8700 & 10100 & 11800 & 12700 & 13650 \\
\hline
\end{tabular}

Hat üzerinde maksimum hız $80 \mathrm{~km} / \mathrm{h}$ olarak belirlenmiştir. Platform bölgelerinde maksimum hız $50 \mathrm{~km} / \mathrm{h}$ 'dir. 750 VDC ile 3. ray sistemini besleyen 7 adet cer gücü merkezi (SS) bulunmaktadır. SS fiderlerinin 3. raya bağlantı noktaları Tablo 2'de verilmiştir.

Tablo 2. Cer besleme bağlantı noktaları

\begin{tabular}{lccccccc}
\hline Cer Gücü Merkezi & SS1 & SS2 & SS3 & SS4 & SS5 & SS6 & SS7 \\
\hline Bağlantı Noktaları (m) & -65 & 2250 & 4750 & 7100 & 9400 & 11700 & 13745 \\
\hline
\end{tabular}

Cer gücü sistemi için diğer parametreler Tablo 3'te verilmiştir.

Tablo 3. Cer gücü sistemi parametreleri

\begin{tabular}{lc}
\hline Parametre & Değer \\
\hline Tek hat 3. ray direnci $(\mathrm{m} \Omega / \mathrm{km})$ & 10 \\
Tek hat ray direnci $(\mathrm{m} \Omega / \mathrm{km})$ & 20 \\
DC bara yüksüz gerilimi $(\mathrm{VDC})$ & 810 \\
Transformatör görünür gücü $(\mathrm{kVA})$ & $2 \times 2500$ \\
Doğrultucu gücü $(\mathrm{kW})$ & $2 \times 2250$ \\
SS iç direnci $(\mathrm{m} \Omega)$ & 5 \\
Pozitif fider direnci $(\mathrm{m} \Omega)$ & 2 \\
Negatif fider direnci $(\mathrm{m} \Omega)$ & 1 \\
Tek hat ray-toprak geçirgenliği $(\mathrm{S} / \mathrm{km})$ & 0,01 \\
\hline
\end{tabular}


Simülasyonlarda 4 vagonlu tren setleri kullanılmıştır. Tren setleri için ana parametreler Tablo 4'te verilmiştir. Tek tren senaryolarında tren yardımcı gücü için $\% 0$ ve $\% 50$ 'lik tüketim oranı kullanılmıştır. Çoklu-tren çoklu-hat senaryolarında \%50 kullanım oranı kullanılmıştır.

Tablo 4. Tren ana parametreleri

\begin{tabular}{lc}
\hline Parametre & Değer \\
\hline Maksimum Hız $(\mathrm{km} / \mathrm{s})$ & 80 \\
Maksimum İvmelenme $\left(\mathrm{m} / \mathrm{s}^{2}\right)$ & 1,0 \\
Maksimum Frenleme İvmesi $\left(\mathrm{m} / \mathrm{s}^{2}\right)$ & 1,1 \\
Jerk (Konfor Katsayısı) Limit $\left(\mathrm{m} / \mathrm{s}^{3}\right)$ & 0,65 \\
Boş Ağırlık (ton) & 146 \\
Tam Ağırlık (ton) & 216 \\
Döner Kütle Oranı (\%) & 10 \\
Uzunluk (m) & 89,6 \\
Yardımcı Güç Sistemi Gücü (kW) & 240 \\
Nominal Çalışma Gerilimi (V) & 750 \\
Maksimum Çalışma Gerilimi (V) & 900 \\
Hızlanma ve Frenlemede Verim (\%) & 89 \\
\hline
\end{tabular}

Tren hareket direnci kuvveti, özellikle doğru boşta gitme stratejisinin belirlenmesi için önemli bir parametredir. Tren imalatçısının vermiş olduğu verilerden elde edilen tren hareket direnci $-\mathrm{h} ı \mathrm{z}$ eğrisi Şekil 3'te verilmiştir.

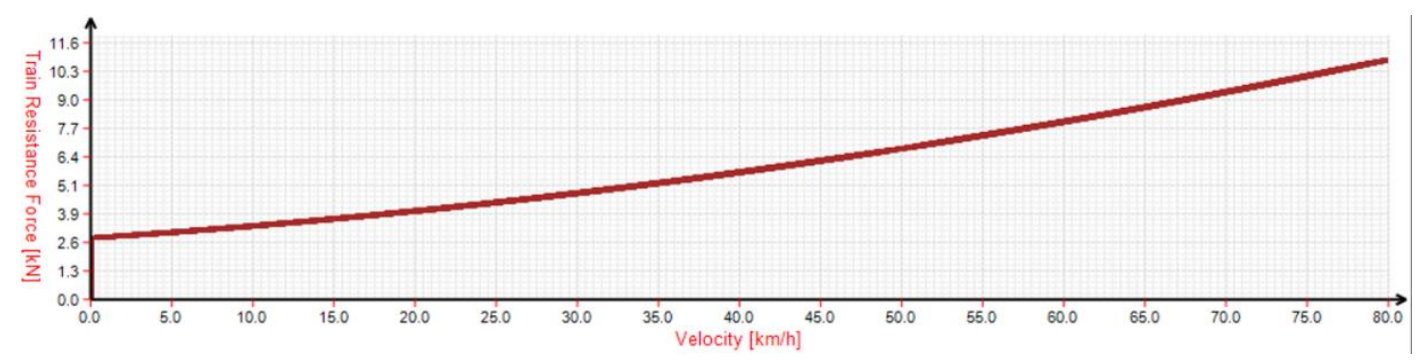

Şekil 3. Tren hareket direnci-hız grafiği

Trenin nominal gerilimdeki hıza bağlı Cer ve Rejeneratif frenleme kuvvet eğrileri Şekil 4'te verilmiştir. Eğriler bir araç için normalleştirilmiştir. Dolayısıyla 4 vagonlu trenin cer kuvveti 240 $\mathrm{kN}$ ve rejeneratif frenlemesi kuvveti $250 \mathrm{kN}$ 'dir.
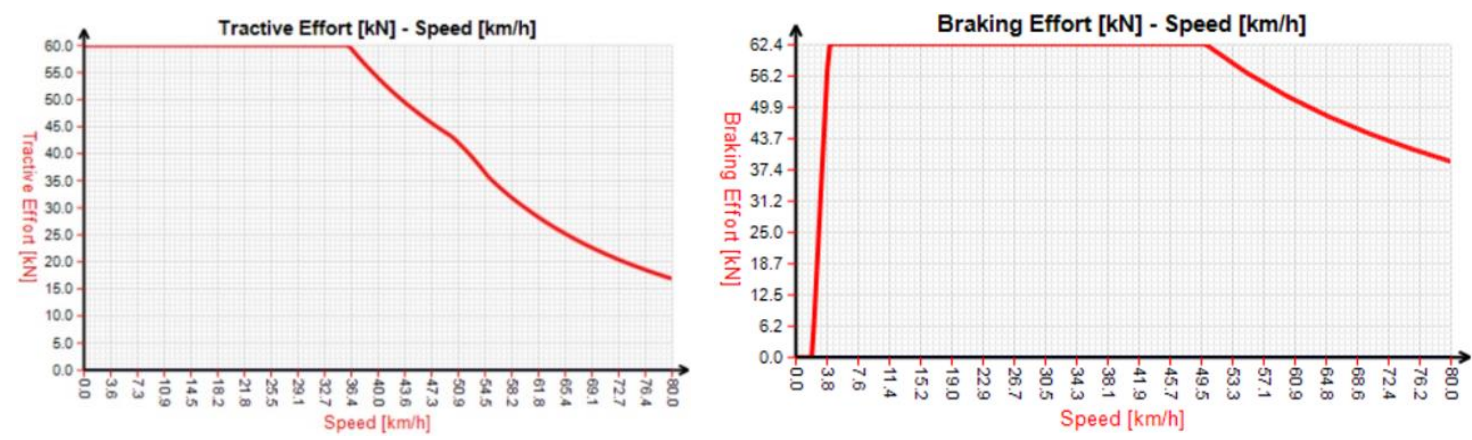

Şekil 4. Trenin cer ve rejeneratif frenleme kuvvet - hız eğrileri. Bir araç için normalize edilmiştir.

Trenin EN 50163 [11] ve EN 50388 [12] standartlarının gereksinimlerini karşıladığ varsayılmaktadır. Bu nedenle, ivmelenme esnasında 600-750 VDC aralığında trenin cer akımı 
3600 A ile sınırlandırılmıştır ve azalan tren gerilimi ile lineer olarak azalarak 500 VDC' de 0 A'e olacağı kabul edilmiştir. Rejeneratif frenleme akımı, tren gerilimi ile sınırlanmamaktadır.

\section{4. İncelenen Enerji Tasarrufu Stratejileri}

$\mathrm{Bu}$ çalışmada gidiş-geliş yönlerinin toplam yolculuk süresini tam güç durumuna göre $\% 4$ arttıran parametre setlerinin ve boşta gitme stratejisinin enerji tüketimi üzerine etkileri incelenmiştir.

Yapılan ilk testlerde tam güç işletmede her iki yöndeki yolculuk süresinin 17dk35s (1055 s) olduğu tespit edilmiştir. Dolayısıyla iki yöndeki toplam yolculuk süresi 2110 s'dir.

Toplam yolculuk süresinin \%4 arttırılması ile toplam yolculuk süresi $84 \mathrm{~s}$ artarak $2194 \mathrm{~s}$ olacaktır.

Not: Seyahat süreleri hesaplanırken her yön için ilk istasyondan çıkış anı başlangıç kabul edilip son istasyonda duruş anı bitiş kabul edilmiştir (birinci istasyon ve son istasyonda bekleme süreleri toplama dahil edilmemiştir.)

\subsection{Performans parametreleri}

Toplam yolculuk süresinin 2194 s civarı gerçekleştiği birçok farklı performans parametre kombinasyonu olabilir. Sinyalizasyon sistemi sağlayıcısı işveren ve işletmeci firma ile birlikte birkaç parametre seti seçer ve bunlar ATS'de ATO Hız Profili olarak tanımlanır. Operatör, operasyon zaman çizelgesinin oluşturulması sırasında bu ATO Hız Profillerinden birini seçebilir.

Bu çalışmada kullanılmış olan farklı performans parametre setleri Tablo 5'te verilmiştir.

Tablo 5. Performans parametre setleri

\begin{tabular}{cccc}
\hline $\begin{array}{c}\text { Set } \\
\text { No }\end{array}$ & $\begin{array}{c}\text { Yavaşlama } \\
\text { İvmesi } \\
\mathrm{m} / \mathrm{s}^{2}\end{array}$ & $\begin{array}{c}\text { Hizlanma } \\
\text { İvmesi } \\
\mathrm{m} / \mathrm{s}^{2}\end{array}$ & $\begin{array}{c}\text { Hiz Limiti } \\
\%\end{array}$ \\
\hline 1 & 1,1 & 1,0 & 100 \\
2 & 0,75 & 1,0 & 100 \\
3 & 1,1 & 0,66 & 100 \\
4 & 1,1 & 1,0 & 89 \\
5 & 1,045 & 0,95 & 92 \\
6 & 0,99 & 0,9 & 94 \\
7 & 0,88 & 0,8 & 98 \\
\hline
\end{tabular}

Tablo 5'te verilmiş olan 1 nolu set, performans parametrelerinin hiçbirinde azalmanın olmadığ 1 tam güç sürüş modudur: Tren, izin verilen maksimum hıza maksimum hızlanma ivmesi ile hızlanır, maksimum hızda hareket eder ve maksimum yavaşlama ivmesi ile frenler.

Tablo 5'deki Set 2-3-4-5-6-7'de tam güç işletmedeki yolculuk süresine göre \%4 artı̧̧a yol açan her bir performans parametresi değeri verilmiştir. Bu değerler yapılan simülasyon testleri ile bulunmuştur. Bunlar; yavaşlama ivmesinin $0,75 \mathrm{~m} / \mathrm{s}^{2}$ veya hılanma ivmesinin $0,65 \mathrm{~m} / \mathrm{s}^{2}$ veya istasyon bölgeleri haricindeki hız sınırlama değerlerinin \%89'a indirgenmesi durumlarıdır.

Benzer şekilde, yapılan farklı testler ile her bir parametrenin aynı anda azaltıldığı üç adet farklı performans parametre kombinasyonu bulunmuştur. Bunlar Tablo 5'deki Set 5-6-7'de verilmiştir. Set 5 'te yavaşlama ve hızlanma ivmeleri \%95'e indirilmiş ve hız limitleri \%92 ile kısıtlanmıştır. Set 6'da \%90 olarak kısıtlanan yavaşlama ve hızlanma ivmesine karşın hız limiti \%94 kısıtlanmıştır. Set 7'de \%80 olarak kısıtlanan yavaşlama ve hızlanma ivmesine karşın hız limiti $\% 98$ kısıtlanmıştır. 


\subsection{Boșta gitme stratejisi}

Teorik çalışmalar, boşta gitmeye dayalı eko-sürüş stratejisinin raylı sistemlerde enerji açısından en verimli stratejilerden biri olduğunu göstermektedir. Douglas ve arkadaşları (2015) demiryolu ağlarında cer enerjisi kullanımını azaltmak için mevcut yöntemleri özetlemekte ve düşük yatırım maliyeti gerektiren eko-sürüşün \%15-35 enerji tasarrufu sağlayabileceğini belirtmektedir. [13]'de, Şekil 5'te gösterilen boşta gitme durumundaki bir trenin tipik hız profilinin tanımını vermektedir.

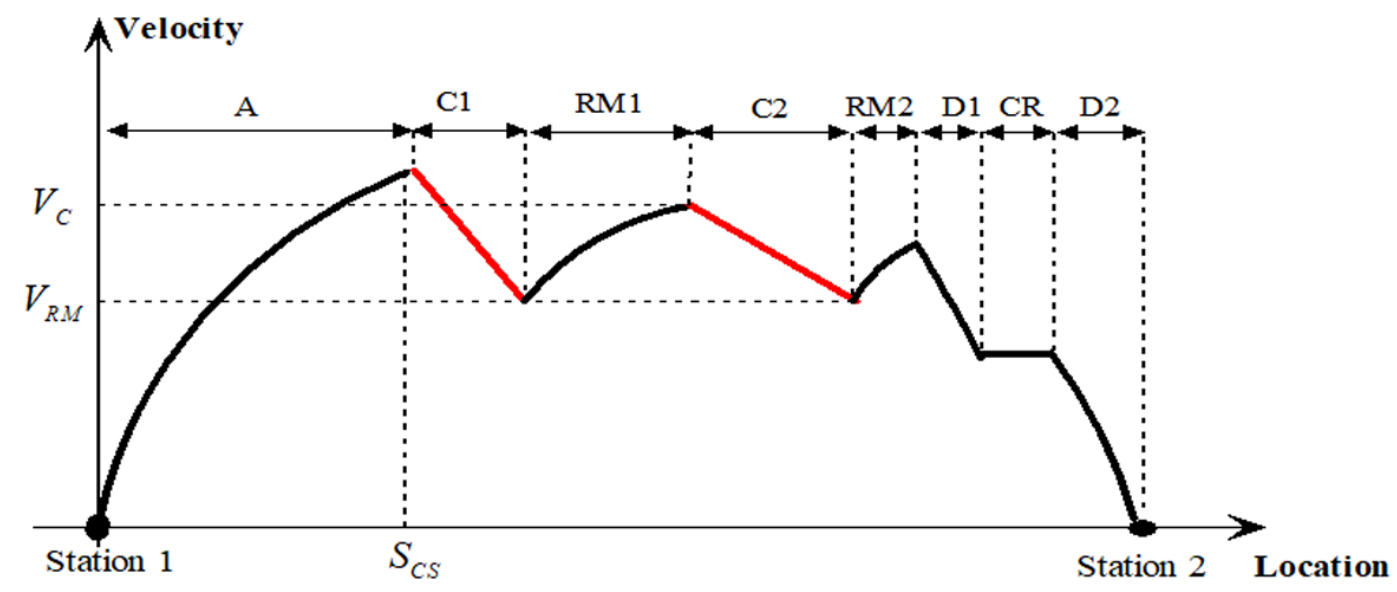

Şekil 5. Boşta gitme stratejisi

Şekil 5'de, tren A bölgesinde hızlanır ve önceden tanımlanmış boşta gitmeye başlama noktasına (Bölge 1 için $\mathrm{S}_{\mathrm{cs}}$ olarak verilmiştir) eriştiğinde hızı tanımlanmış olan $\left(\mathrm{V}_{\mathrm{c}}\right)$ değeri üzerinde ise tren boşta gitmeye başlar (C1 ve $\mathrm{C} 2$ bölgeleri). Trenlerin öngörülenden daha fazla yavaşlamasının önüne geçmek için yeniden hızlanma $\left(\mathrm{V}_{\mathrm{RM}}\right)$ değeri tanımlanmıştır. Bu nedenle tren, yeniden hızlanma bölgeleri RM1 ve RM2'de tekrar hızlanma moduna geçebilir. Tren, D1 bölgesinde önündeki bir hız sınırı için yavaşlar, CR bölgesinde tanımlı olan hız sınırında hareket eder ve D2 bölgesinde önündeki istasyonda durmak için yavaşlar.

Metro uygulamalarında istasyondan istasyona olan mesafeden dolayı, genellikle iki istasyon arasında bir adet boşta gitme bölgesinin tanımlanması yeterlidir. Gerçek bir boşta gitme stratejisinde genellikle dar bir hız bandında ardışık ivme- boşta gitme- yeniden motor- boşta gitme şeklinde bir hareket dizisi bulunmamalıdır.

Yapılan simülasyonlar ile tam güç işletmedeki toplam yolculuk süresinde $\% 4$ artışa neden olan boşta gitme noktaları her iki yön için de belirlenmiştir. Çalışmanın bundan sonraki bazı yerlerinde, boşta gitme stratejisi Set 8 olarak da adlandırılmıştır.

\section{Tren Performans Simülasyonları ve Sonuçlarının Karşılaştırması}

Performans parametre setleri ve boşta gitme stratejisi için elde edilen tren hız profillerini sunmak için PS10 ve PS11 istasyonları arası örnek olarak alınmıştır. Bu iki istasyon arasındaki dikey profil Şekil 6'da verilmiştir.

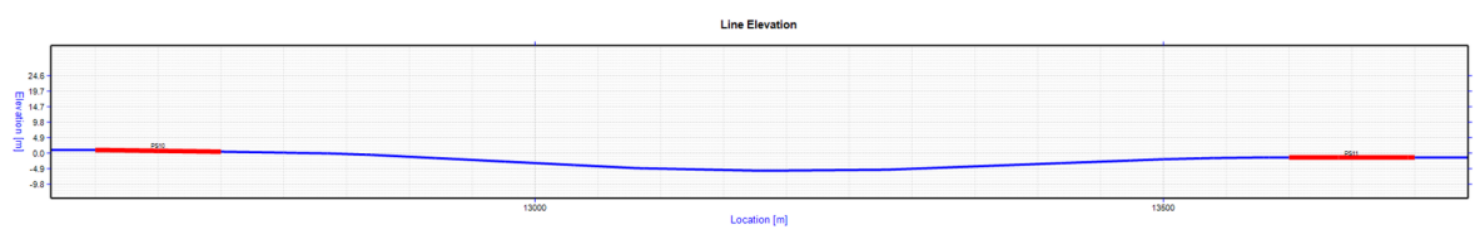


Şekil 6. PS10 ve PS11 arasındaki dikey profil

Tablo 5'te verilen her bir performans parametre seti ve belirlenmiş olan boşta gitme stratejisi için tren performans simülasyonları koşturulmuş ve Hız-Zaman eğrileri Şekil 7'de verilmiştir.

Performans parametre kısıtlamaları ve boşta gitme stratejisinin hız profili üzerindeki etkileri Şekil 7'de açıkça görülmektedir. Tam güç işletme modunda tren bir sonraki istasyona en hızlı şekilde, yaklaşık 67,5 s'de ulaşmaktadır. Performans kısıtlamaları ve boşta gitme stratejisinde ise yolculuk $70 \mathrm{~s}$ civarı sürmektedir.

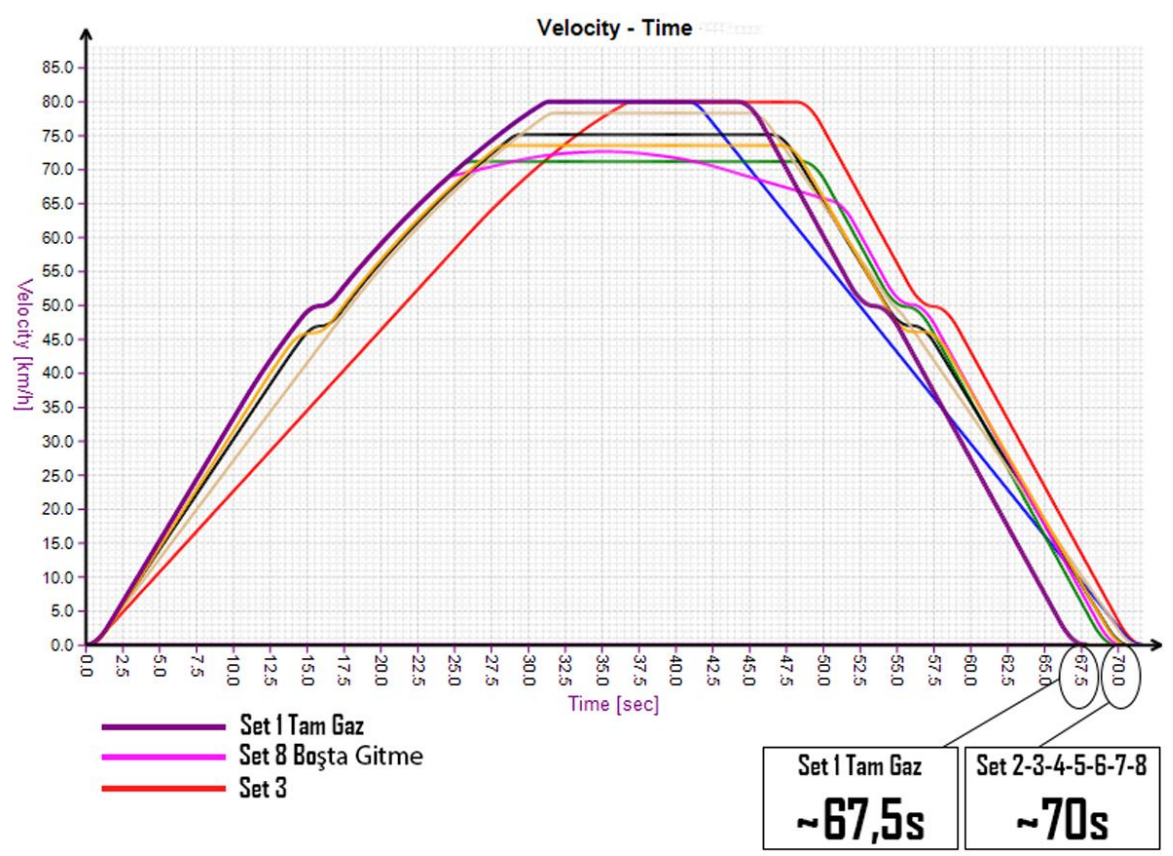

Şekil 7. Performans parametreleri ve boşta gitme stratejisi için PS10-PS11 arasındaki hız-zaman eğrileri

Yukarıdaki çalışma, tren performans simülasyonu ile bütün istasyonları kapsayacak şekilde her iki yönde tekrarlanmıştır. Bütün stratejiler için trenin çektiği enerji ile frenleme esnasında rejenere edebileceği toplam enerjinin farkı olan net enerji tüketimi $\left(E_{n e t}\right)$ değerleri kayıt edilmiştir.

Tren performans simülasyonu (birçok gerçek hayat uygulamasında yapılana uygun şekilde) cer gücü simülasyon yazılımı kullanılmadan tren hareket simülasyonu ile gerçekleştirilen çalışmalara benzemek üzere kullanılmıştır. Tren performans simülasyonunda, enerji tüketimi direkt tren üzerinde ölçülmekte ve dolayısıyla sistemdeki kayıplar hesaba dahil edilmemektedir.

Tren performans simülasyonları tek tren modunda yapıldığından, makul bir karşılaştırma yapabilmek için, tren tarafindan rejenere edilen frenleme enerjisinin tamamının sıfir kayıpla kullanılacağı varsayılmıştır. Sonuçların özeti trenin yardımcı güç sistemi tüketiminin olmadığ 1 (sadece cer enerji tüketimi değerlerinin dikkate alındığı) durum için Tablo 6 ve trenin yardımcı güç sisteminin $\% 50$ yüklendiği durum için Tablo 7'de ayrı ayrı sunulmuştur.

Tablo 6. Tek tren enerji değerleri - tren yardımcı güç sistemi tüketimi olmadığı durum

\begin{tabular}{lcccccccc}
\hline & Set 1 & Set 2 & Set 3 & Set 4 & Set 5 & Set 6 & Set 7 & $\begin{array}{c}\text { Boşta } \\
\text { Gitme }\end{array}$ \\
\hline $\begin{array}{l}\text { Net enerji tüketimi [kWh] } \\
\begin{array}{l}\text { Enerji tüketimindeki } \\
\text { azalma (\%) }\end{array}\end{array}$ & 282 & 259 & 282 & 254 & 257 & 259 & 262 & 228 \\
\hline
\end{tabular}


Tablo 7. Tek tren enerji değerleri - tren yardımcı güç sistemi tüketimi $\% 50$ olduğu durum

\begin{tabular}{lcccccccc}
\hline & Set 1 & Set 2 & Set 3 & Set 4 & Set 5 & Set 6 & Set 7 & $\begin{array}{c}\text { Boşta } \\
\text { Gitme }\end{array}$ \\
\hline $\begin{array}{l}\text { Net enerji tüketimi [kWh] } \\
\begin{array}{l}\text { Enerji tüketimindeki } \\
\text { azalma (\%) }\end{array}\end{array}$ & 212 & 186 & 209 & 181 & 184 & 186 & 189 & 155 \\
& $-9,1$ & 0,7 & $-10,2$ & $-9,1$ & $-8,3$ & $-7,5$ & $-18,0$ \\
\hline
\end{tabular}

Tablo 6 ve 7'deki değerler birlikte incelenince;

- Enerji tüketiminin en düşük olduğu stratejinin boşta gitme stratejisi olduğu ve ikinci en iyi enerji optimizasyon sağlayan Set 4'e göre neredeyse 2 kat fayda sağlayacağ

- Sadece hızlanma ivmesinin azaltılması durumunda enerji azalmasının çok düşük seviye kalacağı ve hatta enerji tüketimini arttırabileceği,

- Trenin yardımc1 tüketim güç sisteminin enerji tüketiminin hesaba katılmaması durumunda enerji optimizasyon yöntemleri ile elde edilecek enerji tasarruf oranının daha fazla (yardımcı güç sistemi kullanım oranına bağlı olmakla birlikte \%40-50 arasında) olarak hesaplanabileceği görülmektedir.

Beklenmedik durumlara karşı toplam yolculuk süresinde tam güç işletmeye göre \%6-8 ilave süre dikkate alan bir operatör için yolculuk süresindeki artış hassas bir değerdir. Bu makalede gerçek hayatta tolere edilerek uygulanabilecek bir değer olan \%4 süre artışı kullanılmış ve tek tren durumu için tren yardımcı güç sistemi tüketiminin de dikkate alındığı durumda, boşta gitme stratejisinde enerji tüketiminin tam güç işletmesine göre \%18 azalacağı görülmüştür.

Bilgi amaçlı olarak Set 1-2-3-4-5 ve boşta gitme stratejisi için trenin doğu yönündeki hız-yer profilleri Şekil 8'de verilmiştir. Performans parametrelerinin ve boşta gitme stratejisinin trenin hız eğrisi üzerindeki etkisi net şekilde görülebilmektedir.

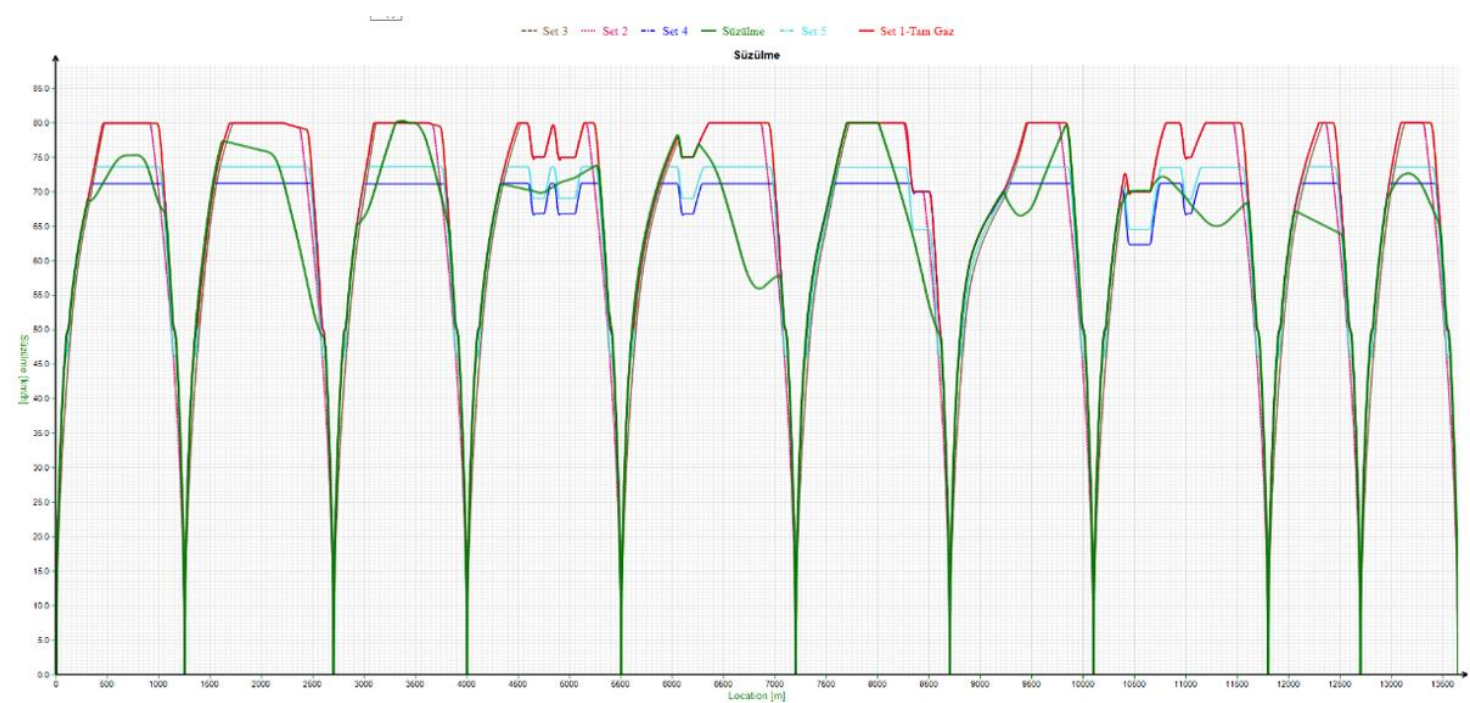

Şekil 8. Set 1-2-3-4-5 performans parametreleri ve boşta gitme stratejisi için doğu yönündeki hız profilleri

\section{6. Çoklu tren çoklu hat cer gücü simülasyon testleri ve sonuçlarının karşılaştırmasıı}

Gerçek işletmede trenler, günlük bir operasyon sırasında farklı sefer aralığı ile çalışır. Farklı yaklaşımların sağlayacağı enerji tasarrufu potansiyelini gerçekçi bir şekilde saptayabilmek için 
rejeneratif frenleme enerjisinin trenler arasında aktarılması ve sistemdeki kayıplar gibi raylı sistem operasyonuna ait birçok hususu dikkate alan çoklu tren çoklu hat cer gücü simülasyonunun yapılması gereklidir. Ayrıca, tren gerilimine bağlı akım/güç sınırlaması ve istasyonlardaki bekleme sürelerindeki farklılıkların da hesaba katılması sonuçların gerçeğe daha fazla yakınması için gereklidir.

$\mathrm{Bu}$ amaçla, çok trenli çok hatlı cer gücü simülasyonları hem performans parametre setleri hem de boşta gitme stratejisi için farklı sefer aralıkları (HT) ile 2 saatlik operasyon süresi için gerçekleştirilmiştir. $\mathrm{Bu}$ simülasyonlarda trenlerin yardım güç sistemi kullanım oranı $\% 50$ alınmıştır. Sonuçların değerlendirilmesinde, $\mathrm{E}_{\text {araç }}{ }_{\mathrm{km}}$ olarak adlandırılan araç*km başına enerji tüketimi ile karşılaştırma yapılması daha anlamlıdır. Bu değer, cer trafo merkezlerinden çekilen toplam enerji miktarının toplam araç kilometre değerine bölümüdür.

Bu çalışmada, 2, 3, 4, 5 ve 10 dakikalık tren sefer aralıkları incelenmiştir. Bu simülasyonlarda iki terminalden de trenler tanımlanmış olan sefer aralıkları gönderilmiştir. Her tren sefer sıklığı için hesaplanan $\mathrm{E}_{\mathrm{ara} a{ }^{*}} \mathrm{~km}_{\mathrm{k}}$ ve enerji optimizasyon senaryoları durumunda elde edilen $\mathrm{E}_{\text {araç }} \mathrm{km}_{\mathrm{km}}$ değerinin tam güç işletmesindekine göre olan değişme oranı $(\Delta \mathrm{E})$ Tablo 8'de verilmiştir. $\Delta \mathrm{E}$ 'nin negatif olduğu değerler, tam güç işletime göre sağlanan enerji tasarrufudur. Tablo 8'den görülebileceği gibi, bazı senaryolarda enerji tüketiminin azalması yerine arttığı anlamına gelen pozitif $\Delta \mathrm{E}$ değerleri de elde edilmiştir.

Tablo 8. Çoklu tren cer gücü simülasyonları için enerji değerleri

\begin{tabular}{|c|c|c|c|c|c|c|c|c|c|c|c|c|c|c|c|}
\hline \multirow{2}{*}{$\begin{array}{l}\mathrm{HT} \\
(\mathrm{dk})\end{array}$} & \multirow{2}{*}{$\frac{\text { Set } 1}{\begin{array}{c}\text { Earaç*km }_{\text {ark }} \\
(\mathrm{kWh})\end{array}}$} & \multicolumn{2}{|c|}{ Set 2} & \multicolumn{2}{|c|}{ Set 3} & \multicolumn{2}{|c|}{ Set 4} & \multicolumn{2}{|c|}{ Set 5} & \multicolumn{2}{|c|}{ Set 6} & \multicolumn{2}{|c|}{ Set 7} & \multicolumn{2}{|c|}{ Boşta Gitme } \\
\hline & & $\begin{array}{l}E_{\text {araç*km }} \\
(\mathrm{kWh})\end{array}$ & $\begin{array}{l}\Delta \mathrm{E} \\
(\%)\end{array}$ & $\begin{array}{c}E_{\text {araç*km }} \text { (km) } \\
(\mathrm{kWh})\end{array}$ & $\begin{array}{l}\Delta \mathrm{E} \\
(\%)\end{array}$ & $\begin{array}{c}\text { Earac*km } \\
(\mathrm{kWh})\end{array}$ & $\begin{array}{l}\Delta \mathrm{E} \\
(\%)\end{array}$ & $\begin{array}{c}\text { Earaç*km } \\
(\mathrm{kWh})\end{array}$ & $\begin{array}{l}\Delta \mathrm{E} \\
(\%)\end{array}$ & $\begin{array}{c}\text { Earaç*km } \\
(\mathrm{kWh})\end{array}$ & $\begin{array}{l}\Delta \mathrm{E} \\
(\%)\end{array}$ & $\begin{array}{c}E_{\text {araç*km }} \\
(\mathrm{kWh})\end{array}$ & $\begin{array}{l}\Delta \mathrm{E} \\
(\%)\end{array}$ & $\begin{array}{c}\text { Earac*km } \\
\text { (kWh) }\end{array}$ & $\begin{array}{l}\Delta \mathrm{E} \\
(\%)\end{array}$ \\
\hline 2 & 3,26 & 3,24 & -061 & 3,53 & 8,28 & 2,94 & $-9,82$ & 3,03 & $-7,06$ & 3,09 & $-5,21$ & 3,23 & $-0,92$ & 2,8 & $-14,11$ \\
\hline 3 & 3,14 & 2,86 & $-8,92$ & 3,08 & $-1,91$ & 2,78 & $-11,46$ & 2,83 & $-9,87$ & 2,86 & $-8,92$ & 2,91 & $-7,32$ & 2,47 & $-21,34$ \\
\hline 4 & 3,45 & 3,38 & $-2,03$ & 3,54 & 2,61 & 3,15 & $-8,70$ & 3,2 & $-7,25$ & 3,26 & $-5,51$ & 3,39 & $-1,74$ & 2,92 & $-15,36$ \\
\hline 5 & 3,39 & 3,11 & $-8,26$ & 3,35 & $-1,18$ & 3,03 & $-10,62$ & 3,11 & $-8,26$ & 3,13 & $-7,67$ & 3,17 & $-6,49$ & 2,69 & $-20,65$ \\
\hline 10 & 3,93 & 3,85 & $-2,04$ & 4,04 & 2,80 & 3,56 & $-9,41$ & 3,67 & $-6,62$ & 3,75 & $-4,58$ & 3,89 & $-1,02$ & 3,22 & $-18,07$ \\
\hline
\end{tabular}

Tablo 8'deki veriler incelendiğinde, Set 2-3-7 performans parametreleri durumunda, $\Delta E^{\prime}$ 'nin genellikle düşük olduğu ve hatta Set 3 için üç sefer aralığ durumunda pozitif olduğu yani enerji tüketiminin azalmadığı, tersine arttığı görülmektedir. Set 4'ün diğer performans parametreleri setlerine göre daha yüksek tasarruf potansiyeli sağlamaktadır.

Tablo 8, boşta gitme stratejisinin tüm sefer aralıklarında çok daha yüksek enerji tasarrufu sağladığını göstermektedir. Özellikle Set 2-3-7 durumları için, performans verileri ile boşta gitme stratejileri arasındaki tasarruf yüzdeleri arasındaki fark çok yüksektir. İşletme sıklığına bağlı olarak, boşta gitme stratejisi \%14,11-21,34 arasında tasarruf sağlarken ikinci iyi olan, Set 4 ile verilmiş olan, indirgenmiş hız sınırlamaları stratejisi ise \%8,7-11,46 arasında enerji tasarrufu sağlamaktadır. $\mathrm{Bu}$ değerler giriş bölümünde verilmiş olan literatürdeki diğer çalışmaların sonuçları ile örtüşmektedir.

Diğer önemli bir çıkarım Tablo 6 ve 7'deki tek tren performans simülasyon sonuçları ile Tablo 8.'deki çoklu tren cer gücü simülasyon sonuçları arasındaki değerlerin karşılaştırılması ile yapılabilir: Tek tren performans simülasyonlarında, trenin yardımcı güç sisteminin kullanım oranının hesaba dahil edilmesi durumunda çoklu tren cer gücü simülasyon sonuçlarına yakın değerler edilmektedir. Dolayısıyla, tek tren performans simülasyonlarında gerçekçi sonuç elde edebilmek için tren yardımcı güç sisteminin enerji tüketimi de hesaplara dahil edilmelidir. 
Tablo 7'de tren yardımcı güç sisteminin tüketiminin hesaba katıldığı tek tren performans simülasyonu ile boşta gitme stratejisinin \%18,0 tasarruf sağlayabileceği bulunmuşken çoklu tren cer gücü simülasyonlarında 3 ve $5 \mathrm{dk}$ tren işletim sıklıkları için elde edilebilecek enerji tasarruf oranının tek tren performans simülasyon sonucuna göre bir miktar daha fazla olacağ 1 gözlemlenmektedir. Bunun sebebinin rejeneratif frenleme enerjisini trenler arası aktarımının cer gücü simülasyonlarında gerçekçi şekilde dikkate alınması ve gerek trenler arası rejeneratif enerji aktarımında gerekse trafo merkezleri ile trenler arasındaki enerji iletimi esnasında sistemde oluşan kayıpların da dikkate alınarak hesaplara dahil edilmesi olduğu öngörülmektedir.

Yukarıdaki tartışma, çoklu tren cer gücü simülasyonu ile tekli tren performans simülasyonlarının karşılaştırılmasında tren yardımcı güç kullanımının hesaplara dahil edilmesinin önemli olduğunu ve ayrıca işletme sıklı̆ğın sonuçları önemli oranda etkilediğini göstermektedir.

Sabit bir seyahat süresi (örneğin \%4) artışı talebi olduğunda enerji verimli sürüş yöntemlerinin etkinlik sıralamasının; boşta sürüş stratejisi (açık ara en etkin yöntem), maksimum hız sınırlaması, yavaşlama-hızlanma ivmelerinin ve maksimum hız sınırının düşürülmesi, frenleme ivmesinin azaltılması ve son olarak hızlanma ivmesinin düşürülmesi olduğu görülmektedir.

Boşta gitme stratejisinde toplam seyahat süresi artışının farklı istasyonlar arasındaki dağılımı ayrı bir konu olup [13] açıklandığı gibi daha çok yokuş aşağı olan bölgelerde kullanımı ile potansiyel enerji tasarruf miktarı artırılabilir. Bu konu ayrı bir makale olarak yayınlanacaktır.

Tablo 8'de görüldügü üzere bu örnek metro hattı için en verimli çalışma durumu 3 dk'lık sefer sıklığı durumunda elde edilmektedir. Başlangıç ve bitiş istasyonlarında $30 \mathrm{~s}$ bekleme süresi kabul edildiğinde toplam döngü süresi tam güç modunda $2170 \mathrm{~s}$ olarak elde edilmektedir. $3 \mathrm{dk}$ 'lık işletme sıklığının sağlanabilmesi için ihtiyaç duyulan tren sayısı 12,1 ve dolayısı ile 13 adet tren kullanma zorunluluğu ortaya çıkmaktadır. 13 tren ile $3 \mathrm{dk}$ 'lık işletme sıklığının homojen sağlanması için toplam döngü süresi $2340 \mathrm{~s}$ olmakta bu da işletmeci firmaya 170 saniye kadar ekstra zaman vermektedir. 4. Bölümde bahsedildiği üzere \%4 süre artış1 için gerekli olan süre 84 s olduğu için $3 \mathrm{dk}$ 'lık işletme sıklığında boşta gitme stratejisi rahatlıkla kullanılabilir.

\section{Sonuç}

Piyasada bulunan CBTC sistemlerinde enerji optimizasyonu yapmak için firmadan firmaya değişebilen birçok alternatif strateji vardır. Bu çalışmada, çoklu/tekli tren çoklu/tekli hat simülasyon aracı kullanılarak iki farklı strateji incelenmiştir. Birinci strateji, performans parametreleri verilerini (frenleme, hızlanma oranları ve maksimum hız sinırı) önceden tanımlanmış kombinasyonlarda düşürmeye dayanır. İkinci strateji ise boşta gitme stratejisine dayanmaktadir.

Makalede, tam güç işletme modundaki toplam yolculuk süresine göre $\% 4$ artışa sebep olan farklı performans parametre setleri ve boşta gitme stratejisi kullanımında enerji tüketim değerindeki değişmeler hem tek tren durumu için tren performans simülasyonu ile hem de farklı işletme sıklıklarında çoklu tren işletimi durumları için cer gücü simülasyonları gerçekleştirilerek incelenmiştir. Bu çalışma sonucunda şu sonuçlara varılmıştır:

- Tek tren performans simülasyonları, raylı sistemin enerji tüketimine direkt etki eden sistemdeki kayıplar ve rejeneratif frenleme enerjisi değişimi gibi hususları hesap edemez, ancak hesaplara belli kabuller çerçevesinde dahil edebilir. $\mathrm{Bu}$ nedenle, tek tren performans simülasyon sonuçları, konu hakkında önceden bilgisi olmayan müşterilere ve operatörlere yanlış yol gösterebilir.

- Boşta gitme stratejisi, incelenen performans parametre seti tabanlı stratejilere kıyasla daha fazla enerji tasarrufu sağlar. Bu nedenle, müşterilerin ve operatörlerin piyasadaki 
mevcut çözümleri sorgulamaları ve şartnamelerinde, bu özellik hakkında, net bir şekilde yazılmış gereksinimler tanımlaması önerilir.

- Kullanılan örnek metro hattında $180 \mathrm{~s}$ işletme sıklığ için tam güç işletme modunda 12.1 tren gerekliliği olduğu hesaplanmıştır. Olası küçük aksaklıklar ve tren regülasyonu gibi hususlar dikkate alınarak 13 tren ile $3 \mathrm{dk}$ işletme yapılacağı düşünülünce boşta gitme stratejisinin işletmeye etki etmeden uygulanabileceği görülmektedir. Benzer durum birçok farklı işletme sıklığı için de geçerlidir. Dolayısıyla, her hat için işletmecinin tam gaz işletme durumuna göre tolere edebileceği ve hatta kullanılacak tren sayısında artışa yol açmayacak bir süre artışı için boşta gitme stratejisi uygulanarak ciddi oranda enerji tasarrufu sağlanabilecektir.

\section{Kaynakça}

[1] A. Gonzalez-Gil, 2014, "A systems approach to reduce urban rail energy consumption," Energy Conversion and Management,2014, 80, 509-524.

[2] H. \& R. Douglas, 2015, "An assessment of available measures to reduce traction energy use in railway networks," Energy Conversion and Management, Nov. 2015, 106, 1149-1165.

[3] M. Botte, L D'Acierno., 2018, "Dispatching and rescheduling tasks and their interactions with travel demand and the energy domain: Models and Algorithms," Urban Rail Transit, November 2018, https://doi.org/10.1007/s40864-018-0090-8.

[4] M. Popescu and A. Bitoleanu, 2019. "A review of the energy efficiency improvement in DC railway systems," Energies, 2019, 12, 1092.

[5] S. Su et. al., 2016, "Evaluation of strategies to reducing traction energy consumption of metro systems using an optimal train control simulation model," Energies, 2016, 9, 105.

[6] IEEE 1474.1, 2004. IEEE Standard for Communications-Based Train Control (CBTC) Performance and Functional Requirements.

[7] M Dominguez et. al, 2010, "Optimal Design of Metro Automatic Train Operation Speed Profiles for Reducing Energy Consumption,” Proc. IMechE Vol. 225 Part F: J. Rail and Rapid Transit, 463-473.

[8] C. Rongwu et. al, 2014, "A genetic algorithm based train speed regulation optimization," WIT Transactions on The Built Environment, Vol 135, 791-802.

[9] S. Açıkbaş, M. T. Söylemez, 2020, "Comparison of main energy efficiency strategies implemented in a communication based train control system," Transport Research Arena

[10]M.T. Söylemez., S. Açıkbaş, 2004, "Multi-train simulation of DC rail traction power systems with regenerative braking, Computers in Railways IX," WIT Press, ISBN 1-85312-715-9, 958-968.

[11]BS EN 50163:2004+A1:2007 Incorporating corrigendum May 2010. Railway applications — Supply voltages of traction systems.

[12]BS EN 50388:2012 Incorporating corrigendum August 2012. Railway applications - Power supply and rolling stock - Technical criteria for the coordination between power supply (substation) and rolling stock to achieve interoperability.

[13]S. Açıkbaş, M.T. Söylemez, 2008, "Coasting point optimisation for mass rail transit lines using artificial neural networks and genetic algorithms," IET Electric Power Applications, 2008, Vol. 2, No. 3, pp. 172-182.

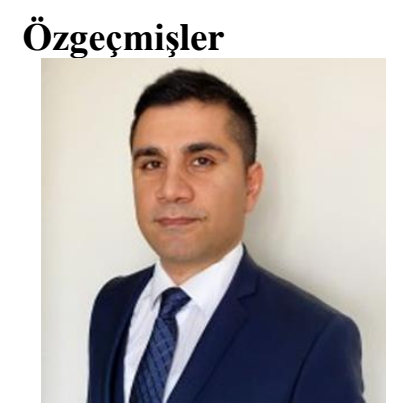

\section{Serhat BOYNUKALIN}

İTÜ Telekomünikasyon mühendisliğinde lisans (2013), Yüksek Lisansını İTÜ Raylı Sistem Mühendisliği Programında (2017) tamamladıktan sonra İTÜ'de Uzaktan Algılama Programında hali hazırda doktora yapmaktadır. Ayrıca Raylı Sistem Mühendisliğinde araştırma görevliliği yapmaktadır. İlgi alanına giren araştırma konuları raylı sistem elektrifikasyon optimizasyonları (işletme planlamaları), sinyalizasyon (GSM-R ve CBTC) ve bu sistemlerin standartlarıdır.

E-Posta: boynukalin@itu.edu.tr 


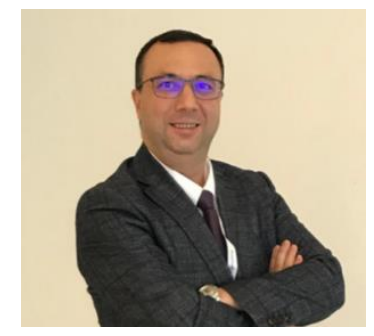

\section{Süleyman AÇIKBAŞ}

Lisans (1992) ve Doktora (2008) eğitimlerini İTÜ Elektrik Mühendisliği Bölümünde tamamlamıştır. Yüksek Lisans (1995) eğitimini ise TCDD bursu ile Manchester Üniversitesinde tamamlamıştır. Meslek hayatına TCDD'de başlamış, Metro İstanbul'da devam etmiş ve ardından Kadıköy-Kartal Metrosu, Doha Lusail LRT ve Kuala Lumpur MRT2 projelerinde çalışmıştır. İTÜ Arı Teknokent'te faaliyet gösteren HI-SIM Teknoloji ve Mühendislik firmasında çalışmaktadır. İlgi alanına giren araştırma konuları raylı sistemlerde enerji verimliliği, cer gücü ve sinyalizasyon sistemleridir.

E-Posta: acikbas@hisim.com.tr

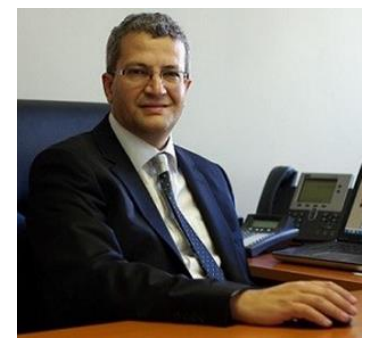

\section{Mehmet Turan SÖYLEMEZ}

İTÜ Kontrol ve Bilgisayar Mühendisliği Bölümü'nden lisans (1991), Manchester Üniversitesi'nden yüksek lisans (1994) ve doktora (1999) derecelerini almıştır. Bir kitap, 25 bilimsel dergi makalesi ve 150 'den fazla ulusal ve uluslararasi bildirinin yazarıdır. Tamamlanmış 8 adet doktora ve 43 yüksek lisans tezine danışmanlık yapmıştır. Otomatik Kontrol Türk Milli Komitesi genel sekreterliği, Shift2Rail Bilimsel Komite üyeliği, İTÜ Raylı Sistemler Ana Bilim Dalı Başkanlığı, IEEE CBTC Standart Komisyonu üyeliği, HI-SIM Teknoloji Mühendislik Ltd. Şti. Genel Müdürlüğü gibi değişik görevleri yürütmektedir.

E-Posta: soylemezm@itu.edu.tr

\section{Beyanlar:}

Bu makalede bilimsel araştırma ve yayın etiğine uyulmuştur.

Tüm yazarların eşit oranda katkısı olmuştur. 